\title{
Globalisation and health inequalities: Can a human rights paradigm create space for civil society action?
}

\author{
Leslie London $^{\mathrm{a}, *}$, Helen Schneider ${ }^{\mathrm{b}}$ \\ ${ }^{a}$ University of Cape Town, School of Public Health and Family Medicine, Anzio Rd, Observatory, Cape Town 7925, South Africa \\ ${ }^{\mathrm{b}}$ University of the Western Cape, School of Public Health, Bellville 7535, South Africa
}

\section{A R T I C L E I N F O}

\section{Article history:}

Available online 3 April 2011

\section{Keywords:}

Human rights

Agency

Globalisation

Civil society

State

Accountability

Health inequalities

Southern Africa

Neoliberalism

\begin{abstract}
A B S T R A C T
While neoliberal globalisation is associated with increasing inequalities, global integration has simultaneously strengthened the dissemination of human rights discourse across the world. This paper explores the seeming contradiction that globalisation is conceived as disempowering nations states' ability to act in their population's interests, yet implementation of human rights obligations requires effective states to deliver socio-economic entitlements, such as health. Central to the actions required of the state to build a health system based on a human rights approach is the notion of accountability. Two case studies are used to explore the constraints on states meeting their human rights obligations regarding health, the first drawing on data from interviews with parliamentarians responsible for health in East and Southern Africa, and the second reflecting on the response to the HIV/AIDS epidemic in South Africa. The case studies illustrate the importance of a human rights paradigm in strengthening parliamentary oversight over the executive in ways that prioritise pro-poor protections and in increasing leverage for resources for the health sector within parliamentary processes. Further, a rights framework creates the space for civil society action to engage with the legislature to hold public officials accountable and confirms the importance of rights as enabling civil society mobilization, reinforcing community agency to advance health rights for poor communities. In this context, critical assessment of state incapacity to meet claims to health rights raises questions as to the diffusion of accountability rife under modern international aid systems. Such diffusion of accountability opens the door to 'cunning' states to deflect rights claims of their populations. We argue that human rights, as both a normative framework for legal challenges and as a means to create room for active civil society engagement provide a means to contest both the real and the purported constraints imposed by globalisation.
\end{abstract}

(c) 2011 Elsevier Ltd. All rights reserved.

\section{Background}

Despite increasing technological innovation and advances in scientific knowledge, the health status of the world's people remains threatened by high morbidity and mortality from longexistent infectious diseases such as malaria and tuberculosis, alongside new epidemics such as HIV/AIDS and avian flu (Boutayeb, 2006; Folch, Hernandez, Barragan, \& Franco-Paredes, 2003) as well as a seemingly relentless growth in non-communicable diseases related to trauma, chronic diseases and cancer, amongst others (Boutayeb, 2006). These health impacts are differentially distributed within and between countries, reflecting severe global health inequalities. In 2005, the life expectancy amongst men in Belgium

\footnotetext{
* Corresponding author. Tel.: +27 21406 6524; fax: +27 214066163.

E-mail addresses: leslie.london@uct.ac.za (L. London), hschneider@uwc.ac.za (H. Schneider).
}

of 76 years was almost double that in Angola (39 years), two countries in which health expenditure per capita differs by a factor of more than 80-fold (US\$ 3133 in Belgium versus \$38 in Angola) (World Health Organisation, 2007). Such inequalities are persistent, if not rising under globalisation, which has encouraged uneven economic benefits to some developing countries, whilst increasing the marginalisation of others (Chapman, 2009; Loewenson, 2001). In the past 30 years, the absolute increase in life expectancy in high-income countries in the Organisation for Economic Cooperation and Development (OECD) was more than 8-fold that experienced in Sub-Saharan Africa where newborns have a life expectancy only slightly more than half of that enjoyed by their counterparts in the OECD countries (Marmot, 2007).

The adverse impacts on health have occurred through various mechanisms. Firstly, it is proposed that gobalisation places severe and unmanageable constraints on economic development needed in developing countries to provide for the underlying determinants of health (Fox \& Meier, 2009). In other words, global inequalities in 
power and the hegemony of neoliberal policy prevent developmentrelated policies from realising public goods for health.

Secondly, globalisation has opened dependent countries' health systems directly to large scale private investment, promoted deregulation of private health care, shrunken public expenditures on social services, facilitated health worker out-migration and reduced the policy room for states to articulate pro-poor policies inconsistent with neoliberalism. For example, USAID has aggressively promoted the role of the private sector in meeting the UN Millennium Development Goals related to reproductive health:

"Governments in developing countries are challenged to meet the health needs of their populations because of financial constraints, limited human resources, and weak health infrastructure. And while universal access to reproductive health care ... is critical to achieve the United Nation's Millennium Development Goals, it is far from becoming a reality. Governments are often major providers of reproductive health services, but inadequate funding greatly limits the availability and quality of the services. The private sector can help expand access to and quality of reproductive health services through its resources, expertise, and infrastructure."

(O'Hanlon, 2009: 1).

However, 'inadequate funding' is as much a consequence of globalisation as are the health inequalities and systems failures that USAID policies purport to address through private provision. Moreover, health inequalities arising from globalisation may be aggravated by national policy failures and flawed decision-making and health system failures often arise from a complex interplay of global forces and national actions.

Nonetheless, globalisation also opens unprecedented opportunities to use international human rights benchmarks to harmonise regulatory standards upwards and to promote health systems improvements (Backman et al., 2008). Under these circumstances, some have argued that the human rights paradigm provides a "foundation for challenging globalization's effects" (Chapman, 2009: 1467) by restructuring, for example the nature of World Trade Organisation (WTO) operations (Forman, 2008a) or the international institutional environment to enable nation states to be active participants in development aid rather than passive recipients of charity (Meier \& Fox, 2008). This implies recognition that human rights are not just about civil and political freedoms but embrace the full spectrum of social and economic entitlements provided for under international human rights law (London, 2007).

So, while international forces under globalisation appear to disempower nation states, rendering them less able to act independently to reduce health inequalities (Katz, 2002), the international identity of a human rights-observing state imposes a range of obligations for measures to realise human rights. This paper focuses on exploring this contradiction in relation to health equity. First, we briefly sketch the nature of state obligations imposed by a human rights framework; secondly, we review whether and how globalisation promotes rights; thirdly, we explore different explanations for why states do not meet their obligations towards the right to health. We test these frames against two case studies, the first based on data from a survey of parliamentarians in Southern and Eastern Africa and the second from struggles around HIV/AIDS in South Africa. Lastly, we conclude by identifying the conditions under which a human rights paradigm can mitigate the effects of globalisation on health inequities.

\section{What does a human rights framework imply?}

Human rights are entitlements people can claim because of their inherent humanity. Typically, they take the form of social or material claims that are universal across cultures and settings and are codified in national and international law. Human rights address fundamental needs and originated in concerns to protect people from an abusive state by limiting state power over individuals. The 'modern' human rights institutional framework guarantees for all of us, irrespective of the countries we live in, some measure of protection against states violating our fundamental freedoms and dignity.While respect for human dignity and freedoms are civil and political rights that lie at the heart of a rights framework, entitlements to social and economic goods and services (so-called socioeconomic rights) are regarded as equally important and indivisible from and interdependent with civil and political freedoms (World Conference on Human Rights, 1993). In the health setting, for example, essential freedoms such as "...equality, the prohibition against torture, privacy, access to information, and the freedoms of association, assembly and movement..." are framed as "... integral components of the right to health.” (United Nations, 2000: clause 3). Disputes over the indivisibility of rights, fuelled by Cold War political divides (Whelan \& Donnelly, 2007), have largely been superseded by increasing international consensus recognizing the indivisibility of human rights (Pettit \& Wheeler, 2005).

Human rights imply duties on a third party to deliver on that entitlement. Typically, the state is the duty bearer though there are recent efforts to extend the purview of rights obligations to nonstate actors such as transnational corporations (Weissbrodt \& Kruger, 2003). State human rights obligations take different forms: a) Firstly, to respect people's human rights, states must desist from passing laws that, for example, discriminate against certain categories of vulnerable persons. The obligation placed on the state is a negative one - to refrain from actions which would violate rights; b) Secondly, states must take actions to protect people from violations perpetrated by third parties, such as it does with public health regulations to protect the population from the effect of corporate pollutants; Lastly, c) states must fulfil rights by taking active steps such as budgeting, providing services and infrastructure to meet its obligations. Active steps imply positive obligations on the State to take specific actions such as providing access to health services. The General Comment 14 elaborates in more detail on the provisions contained in the Covenant relating to health, identifying obligations of immediate effect being those that are not subject to progressive realisation (such as being required to provide access to health care without discrimination), core obligations being provisions for which minimum essential levels of certain rights should be provided, including essential primary health and prohibitions on "any retrogressive measures incompatible with the core obligations." (United Nations, 2000: clause 48).

Rights contained in international conventions become applicable at national level with state ratification, which imposes on a state the obligation to ensure its domestic legislation and programmes put expression to the rights in the convention. Most socio-economic rights are qualified by the concept of progressive realisation, which recognises that states may have limited resources to implement all socio-economic rights to the fullest extent immediately, but should aim to progressively provide such entitlements within a defined period and, in doing so, should prioritise the needs of the most vulnerable.

Rights often need to balance, since rights can conflict, either with each other, or in the way different parties may have conflicting rights. In the former case, state action might violate someone's rights in the interest of meeting the state's obligation to protect, promote or fulfil others' rights. Although the expression of human rights may differ across cultures, there is increasing international consensus that core elements of human rights are to be found across cultures and that a human rights regime helps mediate citizen-state relationships and manage potential conflicts. 


\section{Human rights and health systems}

The hallmark of a human rights approach to health systems is a set of principles (Table 1), which Chapman (2009) argues run contrary to the rationale of neoliberalism. For example, while neoliberalism focuses on the market, treats the conditions needed for health as commodities and benefits the most economically advanced, a human rights approach is based on the recognition of the inherent dignity and worth of the human person, frames the social determinants of health as public goods and focuses on the protection of the most vulnerable and disadvantaged individuals and groups. Some commentators have argued that because of the inherent incompatibilities of human rights approaches with neoliberal capitalism, human rights advocates must, by definition, challenge the dominant model of globalisation (O'Connell, 2007). Health is widely recognised as a public good (Backman et al., 2008; Hunt \& Backman, 2008; UN, 2000) and so will remain incompatible with reliance solely on market-based strategies for its distribution.

Moreover, central to a human rights approach is the notion of accountability (Yamin, 2008), which reframes a claim away from the domain of charity or largesse to that of an entitlement, structured in ways that are intended to preference the most vulnerable in society. Two particular responsibilities of government to render accountability meaningful are to incorporate processes into health policy that enable continuous monitoring of performance in realising the right to health and the resultant obligation to make information about the right to health publicly available in a form understandable to all (Potts, 2008a)

Gable (2007: 534) has argued that there has been an "expanded application of human rights in global health governance" and that this "proliferation is likely to have a positive impact on the governance of global health because it can expand the avenues through which a human rights framework or human rights norms may be used to address and improve health." Indeed, it is not uncommon for the discourse of rights to be found in international agency

Table 1

Essential elements of a human rights approach to health systems (Hunt \& Backman, 2008).

-At the centre is the well-being of individuals, communities, and populations -Is concerned with both processes and outcomes.

- Transparency and access to information

-Participation of individuals and communities in identifying overall strategy, policy-making, implementation, and accountability

-Premised on Equity, equality, non-discrimination and respect for cultural differences

-Addresses both health care and the underlying social determinants of health

-Based on a comprehensive, national plan, encompassing both the public and private sectors, for the development of its health system.

-Takes account of progressive realisation in its priority setting and rationing decisions; uses disaggregated indicators and benchmarks; rebuttable presumption against permissibility of retrogression; must focus on most effective measures

- Recognises and meets Core Obligations: A comprehensive, national plan; access to health-related services and facilities on a non-discriminatory basis, especially for disadvantaged; equitable distribution of health-related services and facilities; effective, transparent, accessible and independent mechanisms of accountability; minimum "basket" services and facilities

-services and facilities of good quality

-continuum of prevention and care and an effective referral system

-a comprehensive, integrated health system but one which is able to balance vertical and comprehensive approaches to delivery

-coordination across sectors; involving public and private actors and NGOs, at different levels (local, national, international)

-Effect international cooperation to protect "global public goods."

-Accessible, transparent, and effective mechanisms of accountability supported by monitoring at national and international levels

-Legal basis for claims programmes and policies such as, for example, the realisation of the Millenium Development Goals (Langford, 2008) or reducing maternal mortality (United Nations Human Rights Council, 2010). However, whether globalisation does contribute to diffusion of human rights norms (Forman, 2008a; Loewenson, 2001) or whether its economic consequences contribute to an undermining of respect for human dignity and denial of entitlements (Cornia, 2001; Watkins, 2002) remains contested (Chapman, 2009). Indeed, there is evidence that even with an increase in the number of countries ratifying international human rights conventions pertaining to health, the act of ratification alone bears little relationship to improved health outcomes (Palmer et al., 2009). Rather, it is the reinforcement of formal legal accountability through strong civil society action that it the best guarantor of realisation of the right to health (Chapman, 2009; Forman, 2008a; London, 2007).

\section{States and human rights obligations under globalisation}

What might be expected from governments committed to human rights when facing threats to human health from the consequences of globalisation? Logically, governments should use regulation to pursue economic policies that prioritise the needs of the most vulnerable of its people and approach policy negotiations regarding international cooperation from that same perspective.

However, there is evidence to the contrary (Katz, 2004,2002; Loewenson, 2001; Meier \& Fox, 2008). The normative explanation for this failure is that most developing country economies cannot follow this path because they are constrained by a neoliberal policy context and by commitments made under various international agreements, or that they lack the political will (Katz, 2002,2004; Yamin, 2008). However, there may be more nuanced reasons why states decline to take action to fulfil the socio-economic rights of their populations. For example, human rights may be perceived to reflect ongoing colonial domination by the 'West' necessitating resistance to what are seen as Eurocentric pressures on indigenous communities to adopt norms consistent with the interests of local elites (Nhlapo, 2000). Alternatively, national political leadership may lack the capacity to exercise oversight over the executive, allowing the bureaucracy to determine the policy space in which the limits of health-related claims can be met. Irrespective, these hypotheses illustrate the dictum that "politics does matter" to the achievement of the highest attainable standard of health (Whitehead, 2008: 1155). States may well be pluralist in how they intervene, thereby presenting both a site of struggle for civil society and a more nuanced source of power in contestation over resources and legitimacy. However, it remains evident that states may not respond in ways that are consistent with their human rights obligations, both explicit obligations arising from formal ratifications of treaties or implicit obligations arising from social consensus and popular expectation.

\section{Methods}

We explore this contradiction through a case study approach, which seeks to investigate a 'phenomenon within its real-life context, especially when the boundaries between phenomenon and context are not clearly evident' (Yin, 2003: 13). The propositions examined are that states renege on meeting obligations to the poorest of their peoples because of both unwillingness and failure of oversight; further, that civil society action is essential to both accountability and oversight of states for their rights obligations. Two Southern African case studies are presented to illustrate contestation of state power in relation to health policy, involving the legislature, the executive and civil society, a framework that comprised our case definition for this study. 
The first case study followed a single-case, embedded design (Yin, 2003). The Network on Equity in Health in East and Southern Africa (EQUINET) is a network of academic, professional, civil society, state and parliamentary institutions within East and Southern Africa that aims to promote shared values of equity and social justice in health. One of its formal themes since 2002 has involved work on health rights. Since 2000, EQUINET has also cooperated with parliamentarians in work on equity in health, consolidated in 2005 with the formation of the Southern and East African Parliamentary Alliance of Committees of Health (SEAPA$\mathrm{COH})$, which aimed to strengthen the role of parliaments in the areas of oversight of budgets, review of legislation and policy and provide leadership for achieving health equity.

The health rights work under EQUINET has involved development of a conceptual framework for understanding the synergy of human rights and health equity, documenting human rights commitment relevant to health made by regional governments, examining the impact of trade agreements on the realization of the right to health in two SADC countries and developing briefs and popular materials to support civil society action for the right to health. In 2008, the health rights theme of EQUINET conducted a survey of parliamentarians and parliamentary staff attending a SEAPACOH workshop) using a semi-structured questionnaire that had been developed with SEAPACOH staff. Questions explored both general progress on parliamentary work on health and specific probing of respondents' knowledge and understanding of human rights and the right to health.Twenty respondents, 15 parliamentarians and 5 committee clerks, from ten committees on health in the region participated in the study though only 19 valid responses were provided and usable for the rights analysis. This sample represented $53 \%$ of all eligible participants and $83 \%$ of country committees attending the workshop and did not include the South African delegation. The interviewer-administered questionnaire explored their views and experiences related to the right to health as well as general information on committees' oversight work (London et al, 2009). The narrative responses to the semistructured questionnaire were analysed through thematic analysis.

The second case study is that of human rights struggles over HIV/AIDS policy in South Africa, which is well known and has, over the past two decades, been the focus of much international media attention (Makgoba, 2002), legislative and court procedures (Forman, 2008b; Heywood, 2003) and public debate (Forman, 2008a; Heywood \& Altman, 2000; Mbali, 2005) including the authors' own work (Fassin \& Schneider, 2003; London, 2002, 2007 and 2008; Schneider, 2002; Schneider \& Stein, 2001). For the purposes of this paper, no new empirical data has been collected. The authors rely on their own previously collected empirical evidence (London, 2007; Schneider, 2002), existing documentation and policy and theoretical literature from the period 2000 to 2009. A systematic review was not undertaken. However, key literature was sourced through PubMed, Social Science Citation Index and Google Scholar focussing on articles published in English. In addition, participant observation and researcher notes of key events and media coverage during this period were utilised.

Case study 1. Southern and East African parliamentarians' understanding of human rights' relevant for oversight.

Respondents reported a wide range of legislative actions, but only in a minority ( 2 out of 10 committees) were rights an explicit subject of review. Indeed, although the kinds of legislation dealt with by committees affected many elements identified by General Comment 14 to the ICESCR as comprising minimum core state obligations (such as child and maternal health, sexual and reproductive health services and obstetric care), state rights obligations were rarely reported as explicitly part of parliamentary considerations. This is consistent with a lack of awareness with only $3(16 \%)$ of the respondents reporting any awareness of the General Comment, despite the fact that the majority of respondents in the region have ratified the ICESCR (Kamupira \& London, 2005). In fact, respondents were more likely to name non-binding agreements such as the SADC protocol on health or the Abuja Declaration or admit to lack of awareness of any international rights agreements (26\% of respondents). Nonetheless, parliamentarians indicated uniform interest in receiving further information on the nature of human rights obligations to strengthen their capacity to exercise oversight over the executive, particularly in budgetary matters.

A second aspect to a rights-based approach to health relates to procedural rights and civil society participation. Parliamentarians reported frequently responding to constituency requests and engaging in processes to draw on public input, for example, in debates in the budgeting process. More than half of the parliamentary respondents noted that civil society submissions to parliament invoked rights arguments, and in all these cases, these rights arguments were acknowledged to have been an important influence on the final decision. These decisions were in diverse areas such as reproductive health rights, disability and transparency in the utilisation of public funding. When interpreting how rights claims were used in influencing decisions, respondents viewed rights as synonymous with actions related to resource allocation - either to increase resource allocation or to improve transparency in resource allocation. Yet, awareness amongst parliamentarians of the applicability of the notion of progressive realization - critical to rationing in a fair manner and to dealing with resource constraints typical of most developing countries - was uniformly poorly understood. Thus, it appeared that while the executive would report to parliament on aspects of their work, no timetables for progressive increase in access to health care or to the conditions needed for health could be examined through these oversight mechanisms.

Rarely, parliamentary representative indicated that they relied exclusively on the executive to bring matters to the political leadership if the matter was 'not in my field' - for example, in responding to whether parliamentary committees played any role in incorporating Trade-related Aspects of Intellectual Property Rights (TRIPS) flexibilities in their national laws. Alternatively, the active involvement of parliamentarians in oversight of health budgets and programmes did draw on human rights arguments in approximately half of the cases cited, though cases that were most successful appeared to achieve victories without reliance on any rights arguments. The picture thus emerges that parliamentary oversight of the executive is exercised mainly in operational terms, and rarely framed in terms of the rights obligations of the state. This is hardly surprising given the weak awareness amongst parliamentarians of what state human rights commitments imply, and, for a minority of cases, to deferring to the executive in matters outside the parliamentarian's expertise.

A particular perspective examined in the study was whether policy makers experienced rights claims as potentially exacerbating inequities by benefiting already powerful interests (Easterly, 2009). Parliamentarians acknowledged a wide range of organizations using rights to advance their interests, including private companies, and organisations with particular sectoral interests, unrelated to vulnerable groups. While in theory, rights claims should preference the poorest and most marginal communities, the reality was that, more often than not, higher-income individuals (which also included politicians, ministers and senior public officials themselves) and organizations were perceived to benefit more than lowincome individuals and communities. Parliamentarians therefore have to translate different stakeholder claims from civil society into a pro-poor agenda but are, in practice, doing so without the benefit of a rights-based framework. 
The case study suggests two mechanisms through which adoption of a human rights approach may strengthen state capacity to counter the adverse impacts of globalization. Firstly, by introducing accountability for meeting national and international norms, a human rights paradigm can strengthen the role of parliamentary oversight over the executive in a manner that prioritises pro-poor protections. Rights commitments can increase leverage for resources for the health sector within parliamentary processes and within cabinet negotiations. Secondly, a rights framework creates the space for civil society action to engage with the legislature to hold public officials accountable.

Case study 2. Human Rights and the HIV/AIDS struggle in South Africa.

Ideas of human rights are central to the post apartheid democratic project in South Africa, which was founded on an internationally acclaimed Constitution and its Bill of Rights which enshrines social and economic rights (including access to health care). In many people's minds, the constitution and a set of associated institutions, most notably a Constitutional Court, form the fulcrum around which a just social order was to be realised, establishing South Africa as a state seemingly committed to human rights.

Unsurprisingly, the judicial system become a central arena for rights contestation in the new South Africa. Nowhere was this more evident than in the field of HIV/AIDS, where "right-based, patient driven AIDS activism" (Mbali, 2005: 213) forcefully brought to the fore the benefits of a constitution premised on a range of rights. Cases defending the rights of people with HIV/AIDS to employment, privacy and dignity have all been successfully fought through the courts. However, most significantly, clauses on the progressive realisation of social and economic rights have enabled powerful claims to be made from civil society with respect to government social policy. For example, a landmark Constitutional Court ruling in 2002 compelled the state to implement a programme of universal access to antiretroviral treatment for the prevention of mother to child transmission (PMTCT) (Heywood, 2003). The success of this case opened the way for a far more significant (from a resource point of view) programme of universal access to antiretroviral therapy currently being implemented.

The influence of these developments has had global impact. Zackie Achmat, AIDS activist and leader of the Treatment Action Campaign, was featured on the front cover of Time Magazine in April 2001 and nominated for a Noble Peace Prize in 2004. It would not be an exaggeration to say that rights-based frameworks in South Africa have contributed to setting new international agendas related to HIV/AIDS as well as other neglected diseases and shaped the approaches to development aid. The 'globalisation' of AIDS activism was made possible by dense networks between civil society, international humanitarian organisations such as Medicins sans Frontieres and a large HIV/AIDS scientific community, that collectively were able to shape consensus on the need for treatment access in the south. The emergence of a new global health architecture (e.g. the Global Fund for AIDS, Malaria and TB, PEPFAR and the Clinton Foundation) originated in these mobilisations. This architecture, in turn, has been brought back to bear on the South African state and other developing countries, highlighting the complex nature and effects of globalisation.

The HIV/AIDS field in South Africa has been marked by intense contestation and repeated resistance by the state to claims made of it - whether relating to individual rights of people with HIV/AIDS or to treatment access (Butler, 2005; Mbali, 2005; Schneider, 2002). These battles, however, were as much about socio-economic rights as about the vexed question of who should and how to speak about HIV/ AIDS - both to define the problem, its extent and causes and to generate appropriate responses (Schneider, 2002). It gave rise to a discourse saturated with 'rights talk' on all sides: on the one hand, the right to individual autonomy, access to treatment and a 'scientific' approach to HIV/AIDS drawing on constitutional notions of individual human rights; on the other hand, appeals to different kinds of entitlements - national sovereignity, unique African responses, cultural dignity and communal rights. This produced, in Butler's (2005) words, two distinct policy paradigms: a mobilisation/ biomedical paradigm and a nationalist/ameliorative paradigm. Each claimed to speak for the poor and vulnerable, and both tapped into deeply held collective experience, even if the elements of crude denialism on the part of President Mbeki were rejected by many.

However, as Mamdani (2000) points out, rights talk can serve to mask power relations. HIV/AIDS in South Africa became framed by the new political elite in terms of their right to rule, and to set the parameters for citizen entitlement. The state reluctantly agreed to adopt an expensive treatment programme only because the political costs of not doing so outweighed the fiscal costs. Policy on HIV/ AIDS treatment prior to this was focused on community-based care through volunteers. Purporting to draw on communitarian ideas of reciprocity and caring in African culture, its real role was to legitimate the widespread practice of turning people with end-stage AIDS away from over-burdened health facilities, and to delegate the management of the dying to households. When universal access to antiretroviral treatment was finally adopted in 2004, minimal investment in monitoring systems made attempts at holding government to account for the programme very difficult. As a result, civil society groups established their own monitoring network to track equity and coverage of ARV access across South Africa during the rollout, illustrating the role identified by Potts (2008a) of civil society monitoring as essential to accountability in a human rights framework.

\section{Institutional accountability and the 'Cunning State'}

In both case studies, therefore, institutional accountability emerges as critical to the success or failure of human rights as a vehicle for health equity. It has been argued that public policy is being removed from "national legislative deliberation" and that the increasing rhetoric of accountability, in the form of attention to good governance, has gone hand-in-hand with increasing unaccountability of transnational corporations, international finance and trade organisations (Randeria, 2003: 306). This new architecture of international relations enables policy actors to evade responsibility by locating accountability outside their own influence. For example, states can blame structural adjustment policies imposed by the International Monetary Fund and international lending agencies can render their own interventive policies invisible by claiming that they do not and cannot interfere with sovereign national decisions.

Randeria (2007) describes this phenomenon of diffused accountability as a "proliferations of actors, arenas, methods and forms of rule making and dispute resolution located at different sites around the world ... no longer co-terminous with the state...". This leads to 'democracy without choices' (Krastev, 2002, cited by Randeria, 2007:5) in that citizens can vote politicians in and out of office but cannot influence public policies. Randeria further frames the concept of a 'cunning state' as being one which enjoys, in reality, considerably more space for decision-making than publicly acknowledged, but whose rhetoric presents itself as subject to the control of international lending organisations. This convenience allows states to be selectively strong when protecting the interests of the elite, but selectively weak when it comes to fulfilling obligations to the poor. Typically, 'cunning states' resist foreign interference in areas such as human rights but claim they are unable to rebuff political pressures around trade and economic policies and 
make sub-optimal use of the limited space afforded to states under international agreements. South Africa's rapid adoption of its own indigenous structural adjustment programme even when effectively free of IMF loan conditionalities, and its dropping of trade barriers in the clothing and agricultural sectors much faster than was required by WTO commitments, justified on the basis that insertion into international markets was essential to its economic recovery post 1994, are examples of such double-standards.

Some evidence emerges from the case studies to support this concept. Few parliamentary committees in the region (London et al, 2009) reported that their countries had incorporated TRIPS flexibilities in their national laws, even though such measures could increase access to health care and help realize core state obligations for the right to health. The South African government, which signed the ICESCR in 1994 in one of its first international treaty commitments, has failed to ratify the convention some 16 years later, an omission that may signify a reluctance to be subjected to international scrutiny for socio-economic rights commitments. In contrast, it is readily willing to follow neoliberal economic and trade policy prescriptions.

Further, the view that the executive should decide which international law should come to parliamentary attention, whilst uncommon amongst parliamentarians, may signify a wider problem of lack of parliamentary expertise exploitable by public officials. Low awareness amongst parliamentary committees of what a rights commitment implies for parliamentary oversight may benefit the executive and may be neither coincidental nor circumstantial. The 'cunning state' will seek as far as possible to avoid being held accountable for rights commitments, generating "conveniently few duties towards their citizens." (Randeria, 2007: 28).

In relation to HIV/AIDS in South Africa, contestation around power gravitated towards different narratives - a civil society narrative which called for state accountability, and a state narrative, albeit a heterogenous one, rebutting rights claims by resort to nationalist autonomy. Whereas an examination of HIV/AIDS struggles in South Africa confirms the proposition that states renege on meeting obligations to the poorest of its peoples because of unwillingness, failure of oversight of the executive emerges more strongly as the underlying reason in the consideration of parliamentarian case study in East and Southern Africa.

It is precisely here that a human rights approach, premised on not only accountability of public officials for their performance (obligations of conduct) and the outcomes of their decisions (obligations of result), but also on political accountability (Yamin, 2008), can counter the 'cunning' state's diffusion of responsibility. Efforts to enhance accountability for the right to health have seen the proposing of health system indicators for the right to health (Backman et al., 2008) and for its progressive realisation (FukudaParr, Lawson-Remer, \& Randolph, 2008), tools to identify the impacts of neoliberal economic policies on socio-economic rights (Balakrishnan \& Elson, 2008) and the proposal of accountability mechanisms for international assistance and cooperation institutionalized through international organizations (Meier and Fox, 2008). However, the question of political accountability highlights the roles of nongovernmental organizations (NGOs), communitybased organizations, the media and networks that cut across class and social location, in effecting such accountability (Potts, 2008a).

\section{Civil society: social movements and the right to health}

Drawing from the Alma Ata declaration on Primary Health Care, the role of community participation in health is widely recognised. Less widely accepted, though, is its normative role within a rights framework, given conflicts over cost-effectiveness and evidence-based policies. Participation becomes key to the realization of the right to health through fair, transparent and meaningful procedures that engage relevant stakeholders and which generate both equitable outcomes and processes (Potts, 2008b; Yamin, 2008).

Evidence elsewhere from the Southern African region (London, 2007) confirms the critical importance of community agency in harnessing rights to a pro-equity agenda. Furthermore, the uptake of rights by social movements is critical to the emergence of new norms. As Lisa Forman highlights in a discussion on access to essential medicines as a core state obligation (not subject to progressive realization), "Social movements are central not just to advancing rights claims but also to creating them."(Forman, 2008a: 40) By generating broad-based social legitimacy for a rights claim, social movements can spur a norm cascade that need not rely on legal accountability to effect policy and programmatic change. For example, the Pharmaceutical Manufacturers Association case against the South African government precipitated a global backlash that spurred the adoption of a human rights discourse in the UN system, whose documents on HIV/AIDS began to talk about access to treatment as a right (Forman, 2008a). The way in which contestation of power between civil society and government over HIV/AIDS unfolded in South Africa helped to shift global agendas with respect to development aid, the pricing of drugs and core health system entitlements in developing countries, confirming the proposition that civil society action is essential to both accountability and oversight of states in relation to rights obligations.

Further, drawing a distinction between "what states are unwilling to do, unable to do, and simply do not know how to do" (Yamin, 2008: 4) may help to identify the extent to which a state is in a position to decide which spaces they continue to control, which they concede to non-state actors and which they negotiate with civil society or global forces (Randeria, 2007). An active civil society engagement with rights claims may also pre-empt the co-option of rights to serving the interests of powerful stakeholders, as may occur when rights claims are viewed as synonymous with litigation (Gloppen, 2008). For this reason, engagement of politically accountable leaders with civil society over health, well reflected in the Southern African parliamentarians study but conspicuously absent or adversarial in the HIV/AIDS case study, may provide some buttressing of states against international neoliberal forces, as well as overcoming the contradictions of a public bureaucracy resistant to rights-based accountability.

Of course, questions can be asked about the parallel accountability of civil society groups (Doyle \& Patel, 2008). For example, many strong advocacy groups located in civil society have no membership base and have no accountability other to their NGO structures or funders (Kilby, 2006), opening them to criticisms that they may act as agents of northern governments or put global policy action ahead of their local constituent base (Newell \& Balfour, 2002). Nonetheless, there is consistent evidence that strong CSO action is absolutely essential to holding government accountable for human rights obligations in health, nowhere more evident than in the case of South Africa's ARV programme (Heywood, 2009; London, 2007).

\section{Conclusion}

It is in the context of this dance of donors and states, in which donors know that states accept human rights standards they have no intention or capacity to implement but to which donors turn a blind eye, that civil society calls for a strong state as a bulwark against globalisation represents a challenge to the idea of the state as being the only site of norm production. Where states manifestly subordinate the health claims of people, particularly marginalised communities, human rights provides civil society tools and 
strategies to challenge state power and its control over the agenda for the distribution of societal resources and benefits. By using the space created by human rights processes (London, 2007), the emancipatory (Randeria, 2007) or transformatory (Heywood \& Altman, 2000) potential of human rights emerges in civil society action to challenge state neglect or omission. Human rights, as both a normative framework for legal challenges and as a means to create room for active civil society engagement provides a fulcrum around which to challenge constraints imposed by globalisation, both real and purported. In doing so, rights struggles recognise both civil and political freedoms and socio-economic entitlements as integrally related.

In recognising human rights' particular contribution to strengthening accountability of nation states, both directly in the planning and implementation of services, and indirectly in engagement with political processes that maximise state accountability, it cannot be assumed that a pro-poor agenda will necessarily emerge. Contestation around power and resources will apply to a human rights paradigm as with any other development framework. However, by establishing strong norms and making explicit the relative interests of different stakeholders, a human rights approach can best serve the interests of the marginalised in preference to other groups. Global networks of civil society can act as powerful countervailing forces to pressures arising from neoliberal discourses by creating and reinforcing space for civil society action. In doing so, a human rights paradigm offers the potential to combat the forces driving health inequalities under globalisation.

\section{Acknowledgements}

The empirical data on parliamentary experiences in Southern and Eastern Africa was drawn from research funded by the Swedish International Development Cooperation Agency (SIDA) and conducted with the support of Southern and East African Parliamentary Alliance of Committees of Health (SEAPACOH) and the Regional Network for Equity in Health in East and Southern Africa (EQUINET). The assistance of Mr Boitumelo Ngkudi and Dr Nayna Manga in data entry and analysis is acknowledged as is the participation of parliamentarians and their staff in this research.

\section{References}

Backman, G., Hunt, P., Kholsa, R., Jaramilla-Strouss, C., Mikuria Fikre, B., Rumble, C., et al. (2008). Health systems and the right to health: an assessment of 194 countries. Lancet, 372, 2047-2085.

Balakrishnan, R., \& Elson, D. (2008). Auditing economic policy in light of obligations of economic and social rights. Essex Human Rights Review, 5, 1-19.

Boutayeb, A. (2006). The double burden of communicable and non-communicable diseases in developing countries. Transactions of the Royal Society of Tropical Medicine and Hygiene, 100, 191-199.

Butler, A. (2005). South Africa's HIV/AIDS policy, 1994-2004: how can it be explained? African Affairs, 104, 591-614.

Chapman, A. R. (2009). Globalization, human rights, and the social determinants of health. Bioethics, 23, 97-111.

Cornia, G. A. (2001). Globalisation and health: results and options. Bulletin of the World Health Organisation, 79, 834-841.

Doyle, C., \& Patel, P. (2008). Civil society organisations and global health initiatives: problems of legitimacy. Social Science \& Medicine, 66, 1928-1938.

Easterly, W. (2009). Human rights are the wrong basis for healthcare. Financial Times, . October 122009.

Fassin, D., \& Schneider, H. (2003). The politics of AIDS in South Africa: beyond the controversies. British Medical Journal, 326, 495-497.

Folch, E., Hernandez, I., Barragan, M., \& Franco-Paredes, C. (2003). Infectious diseases, non-zero-sum thinking, and the developing world. American Journal of Medical Sciences, 326, 66-72.

Forman, L. (2008a). "Rights" and wrongs: what utility for the right to health in reforming trade rules on medicines? Health and Human Rights, 10, 37-52.

Forman, L. (2008b). Justice and justiciability: advancing solidarity and justice through South Africans' right to health jurisprudence. Medical Law, 27, 661-683.

Fox, A. M., \& Meier, B. M. (2009). Health as freedom: addressing social determinants of global health inequities through the human right to development. Bioethics, $23,112-122$.
Fukuda-Parr, S., Lawson-Remer, T., \& Randolph, S. (August 2008). Measuring the progressive realization of human rights obligations: An index of economic and social rights fulfilment. University of Connecticut. Working Paper 8.

Gable, L. (2007). The proliferation of human rights in global health governance. Journal of Law, Medicine and Ethics, 35, 534-544.

Gloppen, S. (2008). Litigation as a strategy to hold governments accountable for implementing the right to health. Health and Human Rights, 10, 21-36.

Heywood, M., \& Altman, D. (2000). Confronting AIDS: human rights, law and social transformation. Health and Human Rights, 5, 149-179.

Heywood, M. (2003). Preventing mother-to-child HIV transmission in South Africa: background, strategies and outcomes of the treatment action campaign case against the minister of health. South African Journal of Human Rights, 19, 278-315.

Heywood, M. (2009). South Africa's treatment action campaign: combining law and social mobilization to realize the right to health. Journal of Human Rights Practice, 1, 14-36.

Hunt, P., \& Backman, G. (2008). Health systems and the right to the highest attainable standard of health. Health and Human Rights, 10, 81-92.

Kamupira, M., \& London, L. (2005). An audit of human rights commitments relevant to heath made by member states of the Southern African Development Community (SADC): Implications for advocacy for health equity and the realisation of the right to health. Harare: EQUINET. http://www.equinetafrica.org/bibl/docs/DIS25rights. pdf Accessed 08.06.09.

Katz, A. (2002). AIDS, individual behaviour and the unexplained remaining variation. African Journal of AIDS Research, 1, 125-142.

Katz, A. (2004). The Sachs report: investing in health for economic development-or increasing the size of the crumbs from the rich man's table? Part I. International Journal of Health Services, 34, 751-773.

Kilby, P. (2006). Accountability for empowerment: dilemmas facing non-governmental organizations. World Development, 34, 951-963.

Langford, M. (2008). Claiming the millennium development goals: A human rights approach. New York: United Nations.

Loewenson, R. (2001). Globalization and occupational health: a perspective from southern Africa. Bulletin of the World Health Organization, 79, 863-868.

London, L. (2002). Human rights and public health: dichotomies or synergies in developing countries? Examining the case of HIV in South Africa. Journal of Law, Medicine and Ethics, 30, 677-691.

London, L. (2007). 'Issues of equity are also issues of rights': lessons from experiences in Southern Africa. BMC Public Health, 7, 14.

London, L. (2008). What is a human-rights based approach to health and does it matter? Health and Human Rights, 10, 65-80.

London L. Mbombo N, Thomas J, Loewenson R, Mulumba M, Mukono A (UCT, TARSC, SEAPACOH) (2009) Parliamentary committee experiences on promoting the right to health in east and southern Africa. EQUINET Discussion Paper 74 UCT TARSC, SEAPACOH: EQUINET, Harare. Accessed 23.03.11 at URL: http://www. equinetafrica.org/bibl/docs/DISS74parlrights09.pdf.

Makgoba, M. W. (2002). Politics, the media and science in HIV/AIDS: the peril of pseudoscience. Vaccine, 15, 1899-1904.

Marmot, M. (2007). Achieving health equity: from root causes to fair outcomes. Lancet, 370, 1153-1163.

Mamdani, M. (Ed.). (2000). Beyond rights talk and culture talk. Comparative essays on the politics of rights and culture. New York: St Martin's Press.

Mbali, M. (2005). The treatment action campaign and the history of rights-based, patient-driven hiv/aids activism in South Africa. In P. Jones, \& K. Stokke (Eds.), Democratising development: The politics of socio-economic rights in South Africa (pp. 213-243). Leiden: Martinus Nijhoff.

Meier, B. M., \& Fox, A. M. (2008). Development as health: employing the collective right to development to achieve the goals of the individual right to health. Human Rights Quarterly, 30, 259-355.

Nhlapo, T. (2000). The Africa customary law of marriaga and the rights conundrum. In M. Mamdani (Ed.), Beyond rights talk and culture talk. Comparative essays on the politics of rights and culture (pp. 136-148). Cape Town: David Phillip.

Newell, P., \& Balfour, S. (2002). Mapping accountability: Origins, context and implications for development. IDS Working Paper 168. Brighton: Institute of Development Studies.

O'Connell, P. (2007). On reconciling irreconcilables: Neo-liberal globalisation and human rights. Human Rights Law Review, 7, 483-509.

O'Hanlon, B. (2009). The vital role of the private sector in reproductive health. Bethesda: PSP One and USAID. at URL. http://shopsproject.org/resource-center/ vital-role-private-sector-reproductive-health Accessed 23.03.11.

Palmer, A., Tomkinson, J., Phung, C., Ford, N., Joffres, M., Fernandes, K. A., et al. (2009). Does ratification of human-rights treaties have effects on population health? Lancet, 373, 1987-1992.

Pettit, J., \& Wheeler, J. (2005). Developing rights?. 36.1 Brighton: Institute of Development Studies.

Potts, H. (2008a). Accountability and the right to the highest attainable standard of health. Human Rights Centre, University of Essex. at URL. http://www.essex.ac.uk/human rights_centre/research/rth/docs/HRC_Accountability_Mar08.pdf Accessed 23.03.11.

Potts, H. (2008b). Participation and the right to the highest attainable standard of health. Human Rights Centre, University of Essex. at URL. http://www.essex.ac. uk/human_rights_centre/research/rth/docs/Participation.pdf Accessed 23.03.11.

Randeria, S. (2003). Glocalization of law: environmental justice, world bank, ngos and the cunning state in India. Current Sociology, 51, 305-328.

Randeria, S. (2007). The State of globalization. legal plurality, overlapping sovereignties and ambiguous alliances between civil society and the cunning state in India. Theory, Culture \& Society, 24, 1-33. 
Schneider, H. (2002). On the fault-line: the politics of AIDS policy implementation in contemporary South Africa. African Studies, 61, 145-167.

Schneider, H., \& Stein, J. (2001). Implementing AIDS policy in post-apartheid South Africa. Social Science \& Medicine, 52, 723-731.

UN (United Nations). (2000). Committee on Economic, Social and Cultural Rights (UNESCR). General comment No. 14: The right to the highest attainable standard of health. UN Document E/C.12/2000/4 p.ragraphs 43-45. UN, Geneva.

United Nations Human Rights Council. (2010). Committee on Economic, Social and Cultural Rights (UNESCR). Preventable maternal mortality and morbidity and human rights: follow-up to Council resolution 11/8. UN Document A/HRC/15/ L.27. UN, Geneva. Accessed on 23rd March 2011 at URL: http://www.who.int/ pmnch/topics/maternal/20100927_hrcmaternalhealth.pdf.

Watkins, K. (2002). Point/counterpoint: making globalisation work for the poor Finance and Development, 39(1). Available at http://www.imf.org/external/pubs/ $\mathrm{ft} /$ fandd/2002/03/watkins.htm.
Weissbrodt, D., \& Kruger, M. (2003). Norms on the responsibilities of transnational corporations and other business enterprises with regard to human rights. The American Journal of International Law, 97, 901-922.

Whelan, D. J., \& Donnelly, J. (2007). The west, economic and social rights, and the global human rights regime: setting the record straight. Human Rights Quarterly, 29, 908-949.

Whitehead, M. (2008). Health should never be merely a means to an economic end. Lancet, 371, 1155-1156.

World Conference on Human Rights. (1993). Vienna declaration and programme of action. Geneva, Switzerland: Office of the United Nations High Commissioner for Human Rights.

World Health Organization. (2007). Countries, health indicators. World health statistics 2007. Available at http://www.who.int/countries/en/ Accessed 24.03.08.

Yamin, A. E. (2008). Beyond compassion: the central role of accountability in applying a human rights framework to health. Health and Human Rights, 10, 1-20.

Yin, R. K. (2003). Case study research: Design and method. Thousand Oaks: Sage. 